\title{
Recent Advances in the Study of Age-Related Hearing Loss: A Mini-Review
}

\author{
Ambrose R. Kidd III Jianxin Bao \\ Department of Otolaryngology, Center for Aging, Washington University School of Medicine, St. Louis, Mo., USA
}

\author{
Key Words \\ Presbyacusis - Age-related hearing loss $\cdot$ Cochlea $\cdot$ Spiral \\ ganglion neuron
}

\begin{abstract}
Hearing loss is a common age-associated affliction that can result from the loss of hair cells and spiral ganglion neurons (SGNs) in the cochlea. Although hair cells and SGNs are typically lost in the same cochlea, recent analysis suggests that they can occur independently, via unique mechanisms. Research has identified both environmental and genetic factors that contribute to degeneration of cochlear cells. Additionally, molecular analysis has identified multiple cell-signaling mechanisms that likely contribute to pathological changes that result in hearing deficiencies. These analyses should serve as useful primers for future work, including genomic and proteomic analysis, to elucidate the mechanisms driving cell loss in the aging cochlea. Significant progress in this field has occurred in the past decade. As our understanding of aging-induced cochlear changes continues to improve, our ability to offer medical intervention will surely benefit the growing elderly population.
\end{abstract}

Copyright ๑ 2012 S. Karger AG, Basel

\section{Introduction}

Age-related hearing loss (AHL), or presbyacusis, is a complex degenerative disease that affects tens of millions of people worldwide. It is one of the most prevalent chron- ic conditions of the aged, afflicting approximately half of those over age 65 in the United States [1]. AHL can cause people to withdraw from friends and become isolated and depressed [2]. Research into the causes of and treatment of presbyacusis is increasingly urgent, as the populations of industrialized countries grow older. For example, between 1965 and 1994, the incidence of presbyacusis in people age $50-59$ increased by $150 \%$ [3].

In the periphery, AHL develops as a result of impaired function of the cochlea, the auditory portion of the inner ear. The cochlea is a spiral-shaped, hollow, bony structure that receives and transmits auditory signals to the brain. The cochlea is filled with fluid that vibrates in response to the movement of the bones of the middle ear. The vibrations of the cochlear fluid are detected by hair cells, which are specialized sensory cells named based on the presence of apical extensions ('hairs') known as stereocilia. The activation of hair cells triggers release of neurotransmitters into the adjacent spiral ganglion neurons (SGNs), which are the primary auditory neurons.

It is well established that there are both genetic and environmental factors that contribute to presbyacusis [4]. Based on postmortem histological analysis, presbyacusis is represented by four subtypes: sensory (loss of hair cell), neural (loss of SGNs), metabolic (atrophy of the stria vascularis), and mechanical (thickening and stiffening of the basilar membrane) [5]. However, because multiple genetic and environmental factors cause presbyacusis, most cases are of mixed pathology and affect multiple cell types. In the laboratory, work often focuses on specific cell types and subtypes of presbyacusis. In this review, we have cho-

\section{KARGER}

Fax +4161306 1234

E-Mail karger@karger.ch

www.karger.com
(C) 2012 S. Karger AG, Basel

0304-324X/12/0586-0490\$38.00/0

Accessible online at:

www.karger.com/ger
Jianxin Bao, $\mathrm{PhD}$

Department of Otolaryngology, Center for Aging

Washington University School of Medicine, Box 8115, 660 South Euclid Avenue St. Louis, MO 63110 (USA)

Tel. +1 314747 7199, E-Mail jbao@wustl.edu 
sen to focus on recent work that has improved our understanding of the cellular and molecular mechanisms that may cause age-related loss of sensory and neural cells in the cochlea. Our goal here is to give an overview of recent progress towards understanding these phenomena.

\section{Noise Exposure and Presbyacusis}

Exposure to damaging levels of noise may be the most studied environmental factor that affects hearing loss. Indeed, exposure to intense noise can cause temporary and permanent hearing loss in humans and animal models [6]. Longitudinal studies showed that presbyacusis is more severe in people thought to have suffered cochlear damage in their youth than in others [6]. It is believed that cochlear damage from noise exposure that causes temporary or no immediate hearing loss may, in fact, accelerate presbyacusis. Unfortunately, it is not possible to fully understand the long-term impact of noise exposure on presbyacusis in humans because so many factors cannot be controlled. However, in animal models, early noise exposure that only causes temporary threshold increases can cause permanent SGN loss and accelerate presbyacusis [7-9]. Anatomically, the loss of SGNs is associated with early loss of synaptic terminals between inner hair cells and SGNs $[8,10]$.

\section{Pathology of Hair Cells and SGNs in AHL}

Patients and animals with AHL typically show degeneration and death of multiple cell types. Unfortunately, it is difficult to understand whether the pathology of hair cells and SGNs are connected [10]. The prevailing view has long been that age-related loss of SGNs occurs as a consequence of hair cell loss, synaptic loss, or both (fig. 1). SGNs do begin to die after mechanical or chemical damage of hair cells, although the rate is species specific. This led to the hypothesis that SGNs rely on hair cells for trophic support $[11,12]$. However, SGN loss can also occur without damage or death of hair cells [13-15]. Thus, it is unclear, in animals with hair cell and SGN loss, whether SGN loss occurs in parallel to or as a consequence of hair cell loss. A conclusive answer to that question has proven difficult to find. For example, C57BL/6 mice, a common model strain with presbyacusis caused by multiple mutations [16-18], showed some mild aberrant pathology of SGNs prior to obvious hair cell loss [19]. However, the researchers could not conclusively say that hair cell degeneration had not begun, or that the abnormal pathology indicated

Recent Advances in the Study of

Age-Related Hearing Loss that SGNs were dying. Our group addressed the question directly by analyzing mice genetically engineered to express either excess or deficient levels of neuregulin-1 (NRG1), which directly modulates synaptic transmission between hair cells and SGNs $[20,21]$. We found that, at 12 months of age, transgenic mice that overexpress NRG1 in SGNs had lower hearing thresholds, while $N R G-/+$ mice had higher hearing thresholds than control mice. We discovered that the improved hearing in these transgenic mice occurred because elevated NRG1 expression enhanced the synaptic transmission between SGNs and hair cells. However, in aged mice, NRG1 overexpression did lead to increased inner hair cell (IHC) death compared to aged NRG1-/+ and control animals. This was in contrast to a similar loss of SGNs in mice overexpressing NRG1-/+ and NRG1 that was not significantly different from that observed in control animals. Together, these experiments mark the first evidence that enhanced synaptic transmission between hair cells and SGNs is unable to prevent SGN loss in aged animals and that age-associated IHC loss does not always cause SGN degeneration [21].

The disconnection between age-related loss of auditory neurons and synaptic changes has also been observed in another system. For example, previous studies identified an age-related functional decline in the medial olivocochlear (MOC) efferent system that occurs before age-related outer hair cell (OHC) loss [22-24]. We recently published work that asks whether age-related synaptic loss of the MOC efferent innervation was independent of age-related OHC loss [25]. We utilized a transgenic mouse model that expresses yellow fluorescent protein under the control of a neuron-specific promoter to facilitate visualization of the synaptic connections between MOC efferent fibers and OHCs. We observed striking synaptic loss between the MOC efferent fibers and the OHCs in aged mice. Importantly, the loss of efferent synapses is independent of age-related loss of OHCs. Thus, age-related loss of efferent synapses does contribute to the functional decline of the MOC efferent system. However, this synaptic loss does not cause OHC loss. This independent mechanism may be a common cellular pathway directing age-related changes in the peripheral nervous system.

\section{Molecular Mechanisms of Presbyacusis}

\section{Oxidative Stress Pathways}

Numerous studies have focused on the hypothesis that age-related mitochondrial dysfunction is an underlying pathology that can cause or hasten presbyacusis. This is 
Fig. 1. Cell loss in the aged cochlea. Schematic representation of hair cells and SGNs in the cochlea of normal individuals (a) and AHL patients (b). Normally, approximately 30 type I SGNs (TI) innervate each IHC. For clarity, innervation of only two IHCs is represented here. Type II SGNs (TII) typically innervate multiple OHCs. In the AHL cochlea (b), a portion of the IHCs, OHC, and SGNs is missing. SGN processes withdraw after IHC death, but SGN death is not obligatory. SGNs can also die independent of IHC loss.

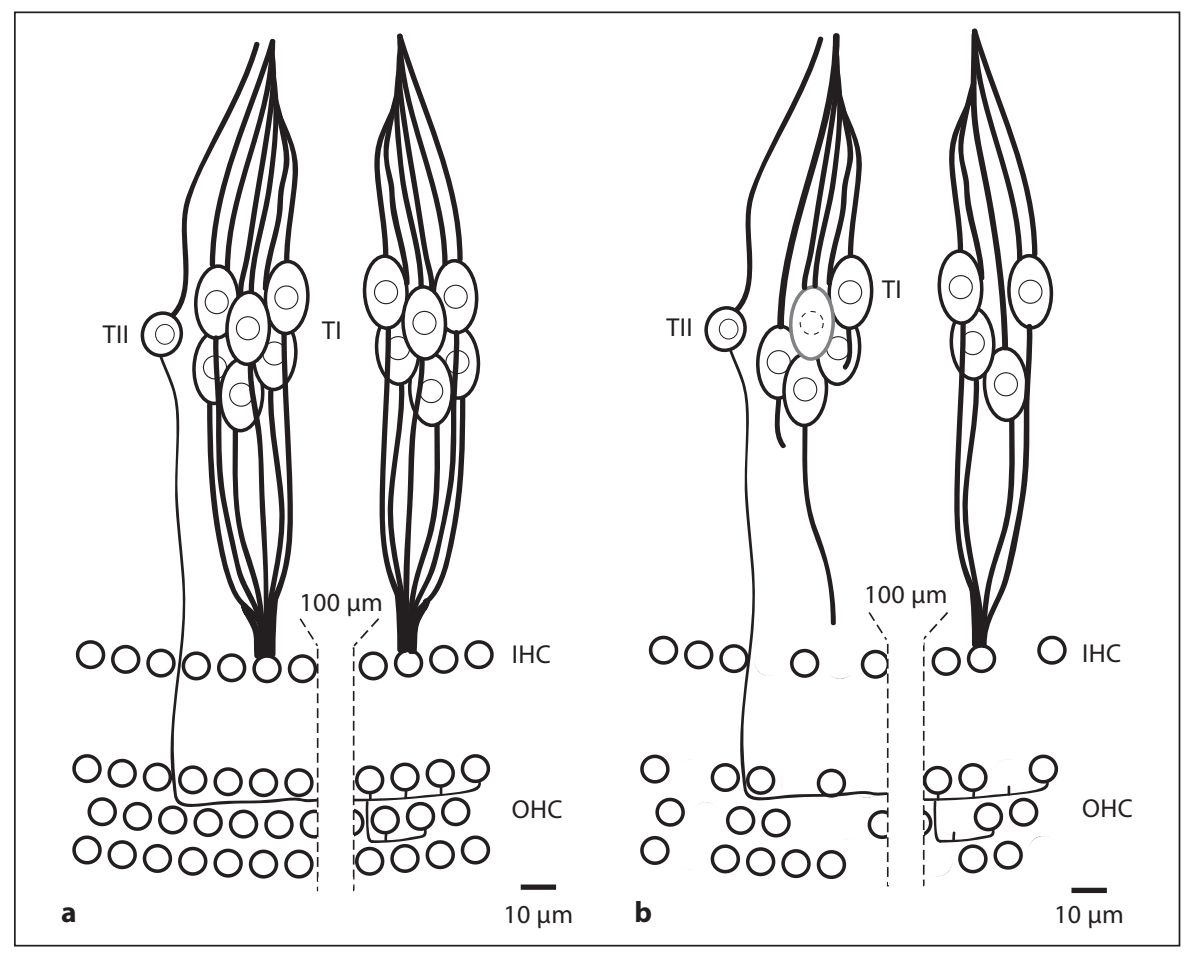

supported by the observation that many genetic conditions linked to hearing loss impair mitochondrial function, and maternally inherited mutations of the mitochondrial genome can cause deafness [26-29]. The cell normally uses a network of proteins and antioxidants to ensure that it has sufficient, but not excessive, reactive oxygen species (ROS) [30]. This network becomes less efficient with age, leading to the increased ROS levels believed to cause a variety of age-associated maladies, including hearing loss [31]. Some groups have searched for, but not yet identified, genetic variants in ROS-signaling genes that are associated with presbyacusis [32, 33]. However, animal models susceptible to oxidative stress display a range of aging-related phenotypes, and results suggest the cochlea is, for unknown reasons, hypersensitive to ROS-induced mitochondrial damage [27]. For example, mice missing the gene encoding $\mathrm{Cu} / \mathrm{Zn}$ superoxide dismutase 1 (SOD1) show premature presbyacusis [34, 35]. Similarly, mice deficient for glutathione peroxidase suffer accelerated AHL and are more sensitive to noise-induced hearing loss (NIHL) [36]. Importantly, the normal system maintains an oxidative balance that cannot be improved by adding exogenous SOD1 and is sufficient for normal function when the protein level is halved $[35,37]$. NIHL may result from a similar sensitivity, as noise exposure is noted to cause elevated ROS levels [38].
Based on the responsiveness of the cochlea to ROS, several groups have sought to prevent or ameliorate presbyacusis by adding exogenous antioxidants. The results are varied, as some studies have shown clear benefit provided by antioxidant treatment $[39,40]$, but others show no effect $[41,42]$. One recent study took advantage of SMP30/GNL rats, which cannot synthesize vitamin C. This allowed the researchers to control vitamin C levels exogenously. Consistent with previous work showing the utility of antioxidants, researchers found that lack of vitamin C accelerated hearing loss and caused loss of SGNs, while diets with additional vitamin $\mathrm{C}$ prevented hearing loss and preserved SGNs [43]. The techniques of the many antioxidant studies vary, and many of the different outcomes may be accounted for by differences in the dosing or delivery of antioxidants. In total, the research to date suggests that oxidative imbalance does contribute to presbyacusis, but also indicates that antioxidant therapy is not a magic elixir that will prevent or treat hearing loss associated with aging.

\section{Cell Death Pathways}

A great deal of the damage caused by ROS produced in the mitochondria occurs in the immediate environment. Not surprisingly, deletions of mitochondrial DNA are more common in presbyacusis patients than in those 
with normal hearing [44]. Some have hypothesized that damage to mitochondrial DNA leads to decreases in energy production that can ultimately cause cell death. Multiple strategies have been employed by researchers attempting to analyze the effect of mutating mitochondrial DNA on aging and cochlear function. For example, some have generated mice that fail to produce a specific DNA polymerase that is required for repair of mutations in mitochondrial DNA. These mice accumulate mitochondrial mutations more rapidly than wild-type mice. Interestingly, these mice also develop premature hearing loss [45, 46]. By contrast, mice subjected to caloric restriction, which slows the age-related decline of mitochondrial function, have delayed presbyacusis $[47,48]$. These findings lend credence to the idea that the cell death that causes presbyacusis results from accumulated damage to mitochondria.

Many research groups have labored to determine whether active or passive mechanisms of cell death occur in the cochleae of those with presbyacusis. Distinguishing different forms of cell death is often complicated, especially in vivo and in aged subjects. Not surprisingly, researchers have found evidence of both necrosis and programmed cell death in aging cochleae. Multiple lines of evidence suggest that the damage and stress to hair cells and spiral ganglion cells results in programmed cell death. For example, TUNEL staining has been used repeatedly to show DNA fragmentation in hair cells and SGNs from aged animals [47, 49]. Several efforts to evaluate cell death mechanisms in the cochlea utilized qPCR and microarray technologies to analyze presbyacusis-associated gene expression changes in the cochlea. Together, they have found that numerous apoptosis-associated genes have altered expression in aged cochleae $[46,50]$. The observations that caloric restriction results in reduced TUNEL-positive cells and mutation of mitochondrial DNA polymerase results in an increased number of TUNEL-positive cells indicate that programmed cell death has a role in cochlear decline [47, 51]. Also, mice that overexpress the human X-linked inhibitor of apoptosis (XIAP) protein have less hearing loss than wildtype siblings. Consistently, fewer hair cells died in mice with excess XIAP [52]. While microscopic analysis showed that dying hair cells in the cochleae of older mice typically appeared to be undergoing apoptotic death, there was also evidence of some cells undergoing necrotic death. As might be expected, these authors found expression of molecular markers consistent with caspasedependent and caspase-independent cell death [53]. By contrast, our group found that neither overexpression of the proapoptotic protein BCL2 or deletion of the gene encoding that protein affected AHL [54]. However, Someya et al. [55] found that mice with a deletion of the proapoptotic gene Bak are resistant to AHL and SGN death. Overall, it appears that certain types of programmed cell death may contribute to age-related loss of cochlear function. However, it is not clear whether other forms of cell death are not relevant. Additional work is required to clarify the role of nonapoptotic cell death and to describe the apoptotic pathway functioning in hair cells and SGNs further.

\section{Calcium-Signaling Pathways}

Aberrant calcium homeostasis has repeatedly been suggested as a contributor to age-related impairment of neuronal function [56-58]. Elderly women using calcium channel blockers were found to have lower hearing thresholds [59], suggesting that calcium regulation contributes to presbyacusis. Hair cells and SGNs have several types of calcium channels, including L- and T-type voltage-gated calcium channels [60-62]. The T-type, or low-voltage, calcium channel family is comprised of three members $\left(\mathrm{Ca}_{\mathrm{v}} 3.1, \mathrm{Ca}_{\mathrm{v}} 3.2\right.$, and $\left.\mathrm{Ca}_{\mathrm{v}} 3.3\right)$, based on their main pore-forming $\alpha$-subunits, $\alpha 1 \mathrm{G}, \alpha 1 \mathrm{H}$, and $\alpha 1 \mathrm{I}$, respectively [63]. The $\alpha 1 \mathrm{G}$ and $\alpha 1 \mathrm{I}$ subunits are weakly expressed in OHCs and IHCs and moderately expressed in SGNs. The $\alpha 1 \mathrm{H}$ subunit is highly expressed in SGNs and absent from OHCs and IHCs [62]. Excitingly, our group recently reported a significant delay of AHL and preservation of SGNs in mice missing the gene encoding the $\mathrm{Ca}_{\mathrm{v}} 3.2$ T-type calcium channel. Additionally, we showed that wild-type mice treated with T-type calcium channel inhibitors had significant preservation of hearing thresholds and SGNs as compared to untreated controls [64]. These T-type calcium channel inhibitors can likewise prevent NIHL [65]. Together, these findings strongly suggest that additional research to study the link between calcium signaling and hearing loss is warranted. Research into the potential therapeutic value of T-type calcium channel inhibitors is ongoing.

\section{Other Pathways}

It is clear that AHL is a complicated disorder that is not uniform in cause or etiology. Thus, many other mechanisms have been implicated as contributors to AHL but have not been studied extensively. These areas, described below, may prove to be fruitful avenues for future endeavors to characterize and prevent AHL. 
Glucocorticoid-Signaling Pathways

The role of glucocorticoid signaling was first suggested when Bao et al. [66] showed that deletion of the $\beta_{2}$-subunit of the nicotinic acetylcholine receptor caused accelerated AHL associated with SGN degeneration. Subsequent work in our laboratory showed that aged mice, but not young mice, lacking high-affinity nicotinic receptors were protected from NIHL. This protection was caused by an agerelated increase in corticosterone and activation of glucocorticoid-signaling pathways, not disruption of efferent cholinergic transmission. Interestingly, chronic elevation of systemic corticosterone levels resulted in extensive SGN loss, indicating a delicate balance of glucocorticoid signaling is required for proper cochlear homeostasis [65]. Similarly, loss of nuclear factor $\kappa \mathrm{B}$, which can function as a key component in the glucocorticoid-signaling pathway, caused premature SGN loss in mice [67].

\section{Sex-Specific Hormone Pathways}

Many researchers have identified sex-specific differences in presbyacusis in humans and animal models [68]. Additionally, estrogen has neuroprotective effects in multiple systems [69]. In 2006, researchers discovered that postmenopausal women using progestin for hormone replacement therapy had hearing loss more frequently than women using other or no treatments [70]. Similarly, combination hormone replacement therapy, using estrogen and progestin, was found to increase the incidence of AHL [71]. The cellular and molecular mechanisms by which progestin impacts cochlear function are unclear at this point. However, this example highlights the fact that our hearing system can be quite sensitive to assaults which do not damage other biological functions.

\section{Stress Response-Signaling Pathways}

The role of stress response proteins in maintaining cochlear function was first identified in studies of NIHL. These studies showed that mice missing heat-shock factor 1 (Hsfl) are less able to recover from noise-induced cochlear damage than control mice [72, 73]. A role for universal stress response proteins in presbyacusis was seen in recent work that demonstrated that the stress-responsive proteins HSP70 and HSP110 are upregulated in the cochleae of control mice (CBA/N) as compared to mice that are prone to AHL (DBA/2J). Interestingly, the authors also showed that addition of geranylgeranylacetone, which induces HSP expression in the cochlea, to the diet of AHL-sensitive mice prevented hearing loss, although the protection was specific to the apical portion of the cochlea [74].

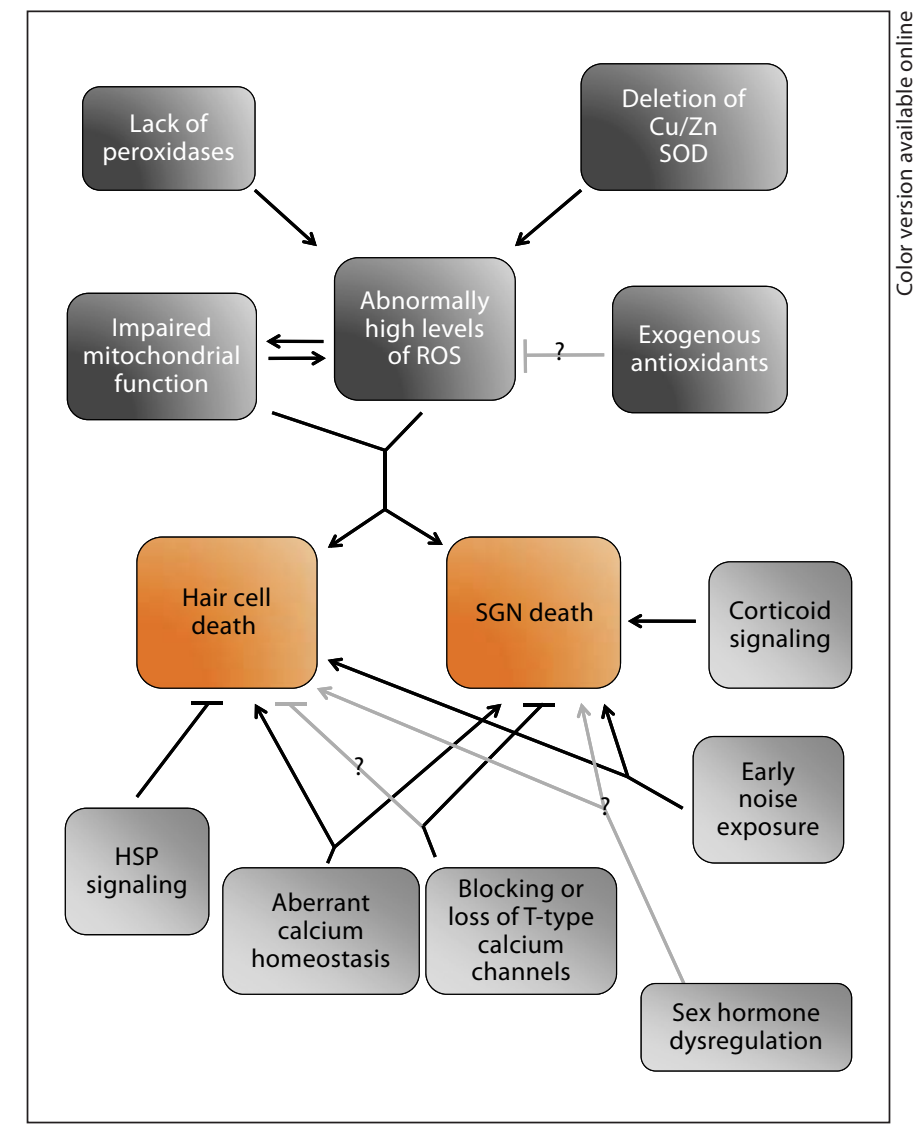

Fig. 2. Mapping the causes of age-related loss of hair cells and SGNs. Contributions to age-related loss of hair cells and SGNs are presented as a flow chart. Causes involving mitochondrial function and ROS are outlined in the top half (dark gray boxes). Other contributions are outlined in the bottom half (light gray boxes). Verified interactions are shown with black lines. Interactions that are likely but not conclusively demonstrated are shown with gray lines.

Glutamate-Signaling Pathways

The search for genetic determinants of presbyacusis led researchers to implicate aberrant glutamate signaling as a potential cause. Specifically, variants in GRM7, the gene encoding metabotropic glutamate receptor type 7 , have been associated with susceptibility to AHL [75]. Although the exact mechanisms by which GRM7 variants may cause hearing loss are unknown, the authors demonstrated that GRM7 is expressed in SGNs and hair cells, and postulate that the causative alleles ultimately result in glutamate toxicity similar to that previously seen in SGN explants [76] (fig. 2). 


\section{Conclusions}

A number of animal models of presbyacusis have been developed to allow detailed study of disease progression and causes. Recent studies in the animal models have effectively revealed numerous cellular and molecular mechanisms that contribute to AHL. It is clear that noise exposure is a critical environmental factor and that genetic aberrations can predispose one to age-related cochlear damage and dysfunction. Also, there is little doubt that damage to mitochondria and their subsequent dysfunction are often precursors to eventual disease phenotypes. Also, calcium signaling, glucocorticoid signaling, sex-specific hormones, and stress response pathways can contribute to presbyacusis. However, it is unclear whether these signaling pathways are universally involved in presbyacusis. Future studies that rely on more detailed analysis, including cell type-specific transgenic models, genomic, and proteomic techniques, to ensure the most detailed understanding and effective treatments for presbyacusis.

\section{Acknowledgements}

The authors wish to thank Drs. Kevin Ohlemiller and Barbara Bohne for helpful discussions while preparing the manuscript. A.R.K. is supported by a grant from the National Organization for Hearing Research Foundation.

\section{References}

1 Gopinath B, Rochtchina E, Wang JJ, Schneider J, Leeder SR, Mitchell P: Prevalence of age-related hearing loss in older adults: Blue Mountains Study. Arch Intern Med 2009;169:415-416.

2 Kalayam B, Meyers BS, Kakuma T, Alexopoulos GS, Young RC, Solomon S, et al: Age at onset of geriatric depression and sensorineural hearing deficits. Biol Psychiatry 1995; 38:649-658.

3 Adams PF, Marano MA: Current estimates from the National Health Interview Survey, 1994. Vital Health Stat 10 1995;193(pt 1):1260.

4 Fetoni AR, Picciotti PM, Paludetti G, Troiani D: Pathogenesis of presbycusis in animal models: a review. Exp Gerontol 2011;46:413425.

5 Gacek RR, Schuknecht HF: Pathology of 16 presbycusis. Int J Audiol 1969;8:199-209.

6 Gates GA, Schmid P, Kujawa SG, Nam B, D'Agostino R: Longitudinal threshold changes in older men with audiometric notches. Hear Res 2000;141:220-228.

7 Kujawa SG, Liberman MC: Acceleration of age-related hearing loss by early noise exposure: evidence of a misspent youth. J Neurosci 2006;26:2115-2123.

8 Kujawa SG, Liberman MC: Adding insult to injury: cochlear nerve degeneration after 'temporary' noise-induced hearing loss. J Neurosci 2009;29:14077-14085.

9 Lin HW, Furman AC, Kujawa SG, Liberman MC: Primary neural degeneration in the guinea pig cochlea after reversible noise-induced threshold shift. J Assoc Res Otolaryngol 2011;12:605-616.

10 Bao J, Ohlemiller KK: Age-related loss of spiral ganglion neurons. Hear Res 2010;264:9397.

11 Takeno S, Wake M, Mount RJ, Harrison RV: Degeneration of spiral ganglion cells in the chinchilla after inner hair cell loss induced by carboplatin. Audiol Neurootol 1998;3: 22 Kim S, Frisina DR, Frisina RD: Effects of age 281-290.

12 Fritzsch B, Fariñas I, Reichardt LF: Lack of neurotrophin 3 causes losses of both classes of spiral ganglion neurons in the cochlea in a region-specific fashion. J Neurosci 1997; 17: 6213-6225.

13 Ryals BM, Westbrook EW: Ganglion cell and hair cell loss in Coturnix quail associated with aging. Hear Res 1988;36:1-8.

14 White JA, Burgess BJ, Hall RD, Nadol JB: Pattern of degeneration of the spiral ganglion cell and its processes in the C57BL/6J mouse. Hear Res 2000;141:12-18.

15 Linthicum FH, Fayad JN: Spiral ganglion cell loss is unrelated to segmental cochlear sensory system degeneration in humans. Otol Neurotol 2009;30:418-422.

16 Noben-Trauth K, Zheng QY, Johnson KR: Association of cadherin 23 with polygenic inheritance and genetic modification of sensorineural hearing loss. Nat Genet 2003;35:21-23.

$\checkmark 17$ Nemoto M, Morita Y, Mishima Y, Takahashi S, Nomura T, Ushiki T, et al: Ahl3, a third locus on mouse chromosome 17 affecting age-related hearing loss. Biochem Biophys Res Commun 2004;324:1283-1288.

18 Keithley EM, Canto C, Zheng QY, FischelGhodsian N, Johnson KR: Age-related hearing loss and the ahl locus in mice. Hear Res 2004; 188:21-28.

19 Stamataki S, Francis HW, Lehar M, May BJ, Ryugo DK: Synaptic alterations at inner hair cells precede spiral ganglion cell loss in aging C57BL/6J mice. Hear Res 2006;221:104-118.

20 Bao J, Lin H, Ouyang Y, Lei D, Osman A, Kim T-W, et al: Activity-dependent transcription regulation of PSD-95 by neuregulin-1 and Eos. Nat Neurosci 2004;7:1250-1258.

-21 Jin D, Ohlemiller KK, Lei D, Dong E, Role L, Ryugo DK, et al: Age-related neuronal loss in the cochlea is not delayed by synaptic modulation. Neurobiol Aging 2011;32:2321.e13-e23. on contralateral suppression of distortion product otoacoustic emissions in human listeners with normal hearing. Audiol Neurootol 2002;7:348-357.

23 Jacobson M, Kim S, Romney J, Zhu X, Frisina $\mathrm{RD}$ : Contralateral suppression of distortionproduct otoacoustic emissions declines with age: a comparison of findings in CBA mice with human listeners. Laryngoscope 2003; 113:1707-1713.

24 Varghese GI, Zhu X, Frisina RD: Age-related declines in distortion product otoacoustic emissions utilizing pure tone contralateral stimulation in CBA/CaJ mice. Hear Res 2005;209:60-67. $A$, Chen AB, et al: Age-related synaptic loss of the medial olivocochlear efferent innervation. Mol Neurodegener 2010;5:53.

26 Kokotas H, Petersen MB, Willems PJ: Mitochondrial deafness. Clin Genet 2007;71:379391.

27 Someya S, Prolla TA: Mitochondrial oxidative damage and apoptosis in age-related hearing loss. Mech Ageing Dev 2010;131: 480-486.

28 Kujoth GC, Bradshaw PC, Haroon S, Prolla TA: The role of mitochondrial DNA mutations in mammalian aging. PLoS Genet 2007;23;3:e24.

29 Lévêque M, Marlin S, Jonard L, Procaccio V, Reynier P, Amati-Bonneau P, et al: Whole mitochondrial genome screening in maternally inherited non-syndromic hearing impairment using a microarray resequencing mitochondrial DNA chip. Eur J Hum Genet 2007; 15:1145-1155.

30 Finkel T: Signal transduction by reactive oxygen species. J Cell Biol 2011;194:7-15.

31 Cui H, Kong Y, Zhang H: Oxidative stress, mitochondrial dysfunction, and aging. J Signal Transduct 2012;2012:646354.
-25 Fu B, Le Prell C, Simmons D, Lei D, Schrader 
-32 Van Eyken E, Van Camp G, Van Laer L: The complexity of age-related hearing impairment: contributing environmental and genetic factors. Audiol Neurootol 2007; 12: 345-358.

- 33 Ateş NA, Unal M, Tamer L, Derici E, Karakaş S, Ercan B, et al: Glutathione S-transferase gene polymorphisms in presbycusis. Otol Neurotol 2005;26:392-397.

34 McFadden SL, Ding D, Reaume AG, Flood DG, Salvi RJ: Age-related cochlear hair cell loss is enhanced in mice lacking copper/zinc superoxide dismutase. Neurobiol Aging 1999;20:1-8.

35 Keithley EM, Canto C, Zheng QY, Wang X, Fischel-Ghodsian N, Johnson KR: Cu/Zn superoxide dismutase and age-related hearing loss. Hear Res 2005;209:76-85.

- 36 Ohlemiller KK, McFadden SL, Ding DL, Lear PM, Ho YS: Targeted mutation of the gene for cellular glutathione peroxidase (Gpx1) increases noise-induced hearing loss in mice. J Assoc Res Otolaryngol 2000;1: 243-254.

- 37 Coling DE, Yu KCY, Somand D, Satar B, Bai U, Huang T-T, et al: Effect of SOD1 overexpression on age- and noise-related hearing loss. Free Radic Biol Med 2003;34:873-880.

38 Ohlemiller KK, Wright JS, Dugan LL: Early elevation of cochlear reactive oxygen species following noise exposure. Audiol Neurootol 1999;4:229-236.

- 39 Heman-Ackah SE, Juhn SK, Huang TC, Wiedmann TS: A combination antioxidant therapy prevents age-related hearing loss in C57BL/6 mice. Otolaryngol Head Neck Surg 2010;143:429-434.

-40 Seidman MD: Effects of dietary restriction and antioxidants on presbyacusis. Laryngoscope 2000;110:727-738.

-41 Bielefeld EC, Coling D, Chen G-D, Li M, Tanaka C, Hu BH, et al: Age-related hearing loss in the Fischer 344/NHsd rat substrain. Hear Res 2008;241:26-33.

-42 Bielefeld EC, Coling D, Chen G-D, Henderson D: Multiple dosing strategies with acetyl L-carnitine (ALCAR) fail to alter age-related hearing loss in the Fischer 344/NHsd rat. J Negat Results Biomed 2008;7:4.

43 Kashio A, Amano A, Kondo Y, Sakamoto T, Iwamura $H$, Suzuki M, et al: Effect of vitamin $\mathrm{C}$ depletion on age-related hearing loss in SMP30/GNL knockout mice. Biochem Biophys Res Commun 2009;390:394-398.

-44 Yamasoba T, Someya S, Yamada C, Weindruch R, Prolla TA, Tanokura M: Role of mitochondrial dysfunction and mitochondrial DNA mutations in age-related hearing loss. Hear Res 2007;226:185-193.

-45 Crawley BK, Keithley EM: Effects of mitochondrial mutations on hearing and cochlear pathology with age. Hear Res 2011;280: 201-208.

- 46 Someya S, Yamasoba T, Kujoth GC, Pugh TD, Weindruch R, Tanokura M, et al: The role of mtDNA mutations in the pathogenesis of age-related hearing loss in mice carrying a mutator DNA polymerase gamma. Neurobiol Aging 2008;29:1080-1092.
47 Someya S, Yamasoba T, Weindruch R, Prolla TA, Tanokura M: Caloric restriction suppresses apoptotic cell death in the mammalian cochlea and leads to prevention of presbycusis. Neurobiol Aging 2007;28:1613-1622.

48 Feuers RJ: The effects of dietary restriction on mitochondrial dysfunction in aging. Ann N Y Acad Sci 1998;854:192-201.

49 Jókay I, Soós G, Répássy G, Dezsõ B: Apoptosis in the human inner ear. Detection by in situ end-labeling of fragmented DNA and correlation with other markers. Hear Res 1998;117:131-139.

50 Tadros SF, D’Souza M, Zhu X, Frisina RD: Apoptosis-related genes change their expression with age and hearing loss in the mouse cochlea. Apoptosis 2008;13:1303-1321.

51 Niu X, Trifunovic A, Larsson N-G, Canlon $B$ : Somatic mtDNA mutations cause progressive hearing loss in the mouse. Exp Cell Res 2007;313:3924-3934.

52 Wang J, Menchenton T, Yin S, Yu Z, Bance $\mathrm{M}$, Morris DP, et al: Over-expression of Xlinked inhibitor of apoptosis protein slows presbycusis in C57BL/6J mice. Neurobiol Aging 2010;31:1238-1249.

53 Sha S-H, Chen F-Q, Schacht J: Activation of cell death pathways in the inner ear of the aging CBA/J mouse. Hear Res 2009;254:92-99.

54 Shen H, Matsui JI, Lei D, Han L, Ohlemiller KK, Bao J: No dramatic age-related loss of hair cells and spiral ganglion neurons in Bcl2 over-expression mice or Bax null mice. Mol Neurodegener 2010;5:28.

55 Someya S, Xu J, Kondo K, Ding D, Salvi RJ, Yamasoba T, et al: Age-related hearing loss in C57BL/6 mice is mediated by Bak-dependent mitochondrial apoptosis. Proc Natl Acad Sci USA 2009;106:19432-19437.

56 Buchholz JN, Behringer EJ, Pottorf WJ, Pearce WJ, Vanterpool CK: Age-dependent changes in $\mathrm{Ca}^{2+}$ homeostasis in peripheral neurones: implications for changes in function. Aging Cell 2007;6:285-296.

57 Toescu EC, Verkhratsky A, Landfield PW: $\mathrm{Ca}^{2+}$ regulation and gene expression in normal brain aging. Trends Neurosci 2004;27: 614-620.

58 Idrizbegovic E, Bogdanovic N, Willott JF, Canlon B: Age-related increases in calciumbinding protein immunoreactivity in the cochlear nucleus of hearing impaired C57BL/6J mice. Neurobiol Aging 2004;25:1085-1093.

59 Mills JH, Matthews LJ, Lee FS, Dubno JR, Schulte BA, Weber PC: Gender-specific effects of drugs on hearing levels of older persons. Ann N Y Acad Sci 1999;884:381-388.

60 Lee S, Briklin O, Hiel H, Fuchs P: Calciumdependent inactivation of calcium channels in cochlear hair cells of the chicken. J Physiol (Lond) 2007;583:909-922.

61 Lopez I, Ishiyama G, Acuna D, Ishiyama A, Baloh RW: Immunolocalization of voltagegated calcium channel alphal subunits in the chinchilla cochlea. Cell Tissue Res 2003;313: 177-186.

62 Shen H, Zhang B, Shin J-H, Lei D, Du Y, Gao $\mathrm{X}$, et al: Prophylactic and therapeutic functions of T-type calcium blockers against noise-induced hearing loss. Hear Res 2007; 226:52-60.

63 Perez-Reyes E, Cribbs LL, Daud A, Lacerda AE, Barclay J, Williamson MP, et al: Molecular characterization of a neuronal low-voltage-activated T-type calcium channel. Nature 1998;391:896-900.

64 Lei D, Gao X, Perez P, Ohlemiller KK, Chen C-C, Campbell KP, et al: Anti-epileptic drugs delay age-related loss of spiral ganglion neurons via T-type calcium channel. Hear Res 2011;278:106-112.

-65 Shen H, Lin Z, Lei D, Han J, Ohlemiller KK, Bao J: Old mice lacking high-affinity nicotine receptors resist acoustic trauma. Hear Res 2011;277:184-191.

66 Bao J, Lei D, Du Y, Ohlemiller KK, Beaudet $\mathrm{AL}$, Role LW: Requirement of nicotinic acetylcholine receptor subunit beta2 in the maintenance of spiral ganglion neurons during aging. J Neurosci 2005;25:3041-3045.

67 Lang H, Schulte BA, Zhou D, Smythe N, Spicer SS, Schmiedt RA: Nuclear factor kap$\mathrm{paB}$ deficiency is associated with auditory nerve degeneration and increased noise-induced hearing loss. J Neurosci 2006;26: 3541-3550.

68 Willott JF, Bross L: Effects of prolonged exposure to an augmented acoustic environment on the auditory system of middle-aged C57BL/6J mice: cochlear and central histology and sex differences. J Comp Neurol 2004 May 3;472:358-370.

-69 Garcia-Segura LM, Azcoitia I, DonCarlos LL: Neuroprotection by estradiol. Prog Neurobiol 2001;63:29-60.

-70 Guimaraes P, Frisina ST, Mapes F, Tadros SF, Frisina DR, Frisina RD: Progestin negatively affects hearing in aged women. Proc Natl Acad Sci USA 2006;103:14246-14249.

71 Price K, Zhu X, Guimaraes PF, Vasilyeva ON, Frisina RD: Hormone replacement therapy diminishes hearing in peri-menopausal mice. Hear Res 2009;252:29-36.

72 Sugahara K, Inouye S, Izu H, Katoh Y, Katsuki K, Takemoto T, et al: Heat shock transcription factor HSF1 is required for survival of sensory hair cells against acoustic overexposure. Hear Res 2003;182:88-96.

73 Fairfield DA, Lomax MI, Dootz GA, Chen S, Galecki AT, Benjamin IJ, et al: Heat shock factor 1-deficient mice exhibit decreased recovery of hearing following noise overstimulation. J Neurosci Res 2005;81: 589-596.

74 Mikuriya T, Sugahara K, Sugimoto K, Fujimoto M, Takemoto T, Hashimoto M, et al: Attenuation of progressive hearing loss in a model of age-related hearing loss by a heat shock protein inducer, geranylgeranylacetone. Brain Res 2008;1212:9-17.

75 Friedman RA, Van Laer L, Huentelman MJ, Sheth SS, Van Eyken E, Corneveaux JJ, et al: GRM7 variants confer susceptibility to agerelated hearing impairment. Hum Mol Genet 2009;18:785-796.

76 Steinbach S, Lutz J: Glutamate induces apoptosis in cultured spiral ganglion explants. Biochem Biophys Res Commun 2007;357:14-19. 